\title{
ELECTRO-OSMOSIS DEWATERING OF COAL SLUDGE
}

\author{
Sonali Samanta ${ }^{1}$, Piyush Kr.Gupta ${ }^{2}$, Puspendu Sardar ${ }^{3}$, Avijit Ghosh ${ }^{4}$ \\ ${ }^{123}$ Department of Chemical Engineering, Haldia Institute of Technology, Haldia-721657, India \\ ${ }^{4}$ Corresponding Author, Assistant Professor, Department of Chemical Engineering, Heritage Institute of Technology, \\ Kolkata, West Bengal, E-Mail: avijit.ghosh@heritageit.edu
}

\begin{abstract}
In waste treatment process, decreasing of water load from the coal sludge is economical and feasible before disposal. Electroosmosis dewatering (EOD) is more energy saving and effective process over other conventional dewatering process. Draining of water from the sludge by generating potential gradient in between two electrodes which were placed in the sludge; is called electro-osmotic dewatering process. A direct current $(D C)$ was used to create that potential difference. This experiment was done by dewatering fine coal sludge using two copper disks as electrodes. It is reported that the flow rate of dewater is proportional to the potential difference between two electrodes and the zeta potential of the sludge particle ${ }^{[2]}$. In this study, the voltage is increased from $40 \mathrm{~V}$ to $100 \mathrm{~V}$ with constant current (1.1 Amp) supply. The zeta potential of the coal particle is increased by adding $1 \%, 2 \%$ and $5 \%(\mathrm{w} / \mathrm{v})$ sodium hydroxide $(\mathrm{NaOH})$ solution, respectively. The volume of water removed, \% moisture content of coal slurry after EOD, volume of water evaporated from the hot electrode surface, and energy consumption are measured for each case. It is observed that as the increasing $\mathrm{NaOH}$ concentration and the potential difference in the slurry, the \% moisture content of slurry is reduced after EOD. The moisture content of the slurry is measured at 5\% NaOH for $100 \mathrm{~V}$ is around $19.7 \%$ which is approximately $6 \%$ lower than as compared to without using caustic solution under same operating condition. The energy used for the removal of above moisture content (19.7\%) is around $5 \mathrm{KWh} / \mathrm{Kg}$ of dewater, which is $54 \%$ less than the thermal processing of sludge.
\end{abstract}

Keywords: Electro Osmotic; Dewatering; Moisture Content

\section{INTRODUCTION}

The reducing the water load from the waste coal sludge is most essential process for any coal based plant for the efficient use of dried coal as fuel. There are various techniques available for the removal of water content from the coal. Most of the plants follow the conventional dewatering process mechanical forces including vacuum filtration, centrifuge, and belt filter press. The electroosmotic dewatering (EOD) process is considered most efficient over these conventional dewatering processes as an alternative energy saving [1]. It can be also efficient as compared to thermal processing of sludge forde watering 2

The electro-osmotic dewatering process can be classified into the removal of water from the sludge applying electric field using direct current source between two electrodes which were placed in the sludge. The basic principle of electro-osmotic dewatering process is attributed to the electric double layer theory [3]. The coal particles are negatively charged relative to water. The sludge water is splits into positive hydrogen ion $\left(\mathrm{H}^{+}\right)$and negative hydroxyl ion $\left(\mathrm{OH}^{-}\right)$with the help of applied potential. In consequence, part of the $\mathrm{H}^{+}$ions is attracted by the negative charge of coal particles to surface, which is neutrally charged. This combined layers of anion of the coal particle and cation of the water is called double layer. The $\mathrm{H}^{+}$ions and $\mathrm{OH}^{-}$ions start migrate towards cathode and anode, respectively due the particle surface is neutral charge. The greater ionic mobility of $\mathrm{H}^{+}$ion than that of $\mathrm{OH}^{-}$ion, results the bulk flow of water towards the cathode [4].

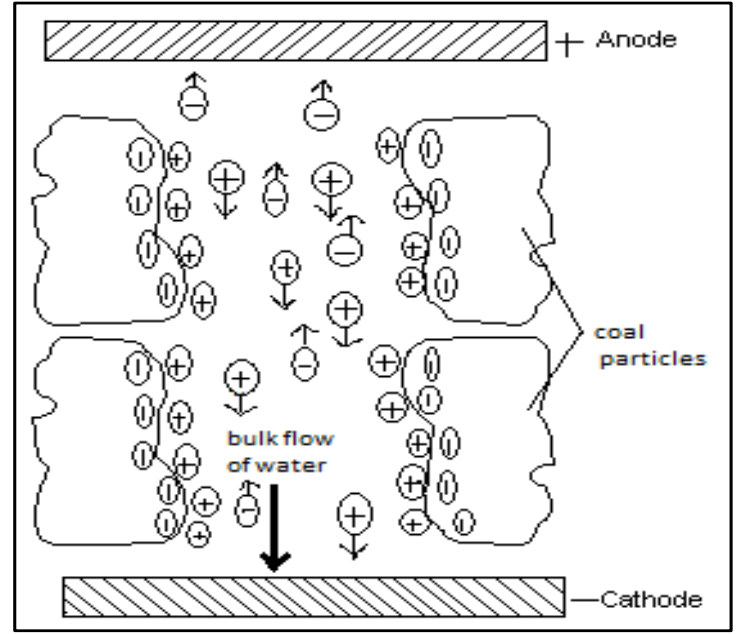

Fig-1: Electrokinetic phenomena of electro-osmosis dewatering process.

The schematic of the electro kinetic phenomena of the coal sludge is shown in fig. 1 .

It can be seen that the presence of electrical field, a potential difference is generated between surface of the coal particle and the adjacent layer of the water. This potential difference is called zeta potential. The zeta potential gradually reduced as ion concentration gradually increased as the dewatering proceeds and hence reduced the dewatering rate [5]. Moreover, it can also be noted that as the increase of $\mathrm{pH}$ of the sludge can increase the zeta potential and the dewatering rate [6]. 


\section{EXPERIMENT}

\subsection{Materials}

$100 \mathrm{gm}$ coal sludge was prepared by adding $50 \mathrm{ml}$ of water in $50 \mathrm{gm}$ coal powder. Sodium hydroxide $(\mathrm{NaOH})$ was procured from Merck. One perforated copper disk and one solid copper disk as an electrodes was procured from market.

\subsection{Method}

The perforated copper disk followed by a filter paper was first placed on the buckhner funnel. The prepared coal sludge was poured into the funnel. Then the solid copper disk kept inside the sludge. This solid disk was slightly press from the top to ensure the good contact between the electrode and sludge. A $100 \mathrm{ml}$ measuring cylinder was placed at the outlet of the funnel to measure the volume of dewater. The experiment was done by varying the voltage from $40 \mathrm{~V}$ to $100 \mathrm{~V}$ with 1.1 Ampere constant current supply along with adding $1 \%, 2 \%$, and $5 \%$ (w/v) sodium hydroxide solution, respectively with the coal sludge.

The volume of water removed, \% moisture content (MC) of coal slurry after EOD, volume of water evaporated from the hot electrode surface, and energy consumption are measured for each case. The dewatering duration was kept 30 minutes, which is constant for all experiments. The percent $(\%)$ of moisture content (MC) of coal slurry after EOD was evaluated using taking some amount of wet sample in hot air oven at $110^{\circ} \mathrm{C}$ for 1 hour. The volume of water evaporated from anode surface is calculated using below equation.

Volume of water evaporated from the hot anode surface $=$ \{initial water content in the coal slurry - (volume of water removed + water content in coal slurry after EOD)\}

\subsection{Experimental set-up}

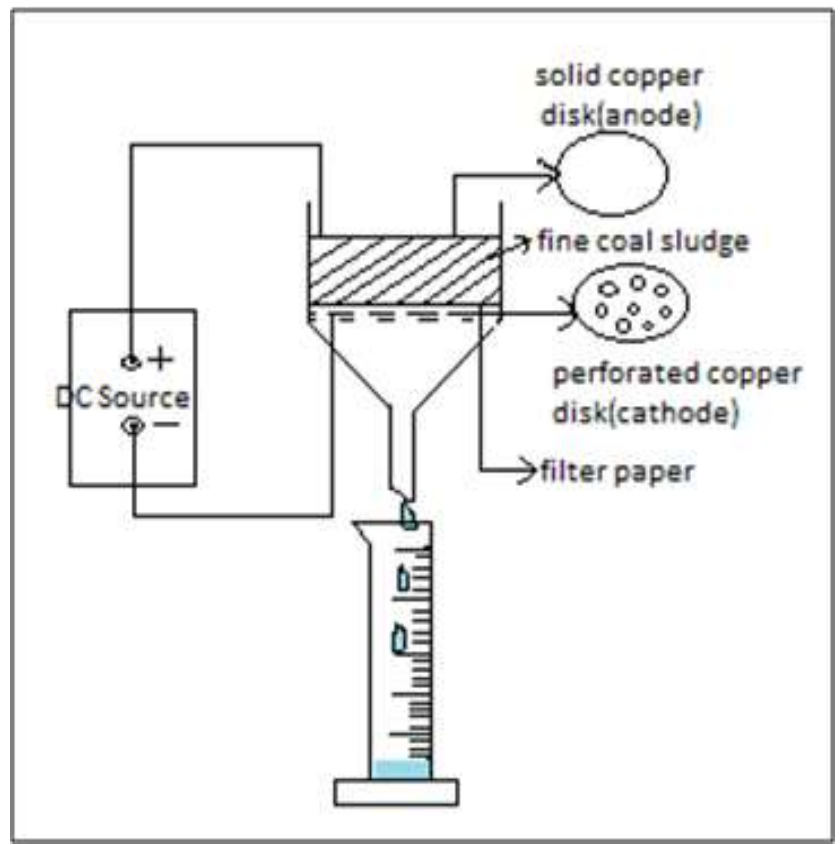

Energy consumption was measured by using the following equation,

$$
\mathbf{E}=\frac{V I d t}{M w} \frac{K W h}{\text { Kgofdewater }}
$$

Where, E=Energy consumption for Electro-osmotic dewatering $(\mathrm{KWh} / \mathrm{Kg}$ of dewater), $\mathrm{V}=$ Applied voltage (volt), I=Applied current (Amp.), dt=duration of dewatering process (hour), $\mathrm{M}_{\mathrm{w}}=\mathrm{Kg}$ of water removed by dewatering process $(\mathrm{Kg})$

\section{RESULTS AND DISCUSSION}

\subsection{Effect of Time on Electro-Osmotic Dewatering:}

It was observed that the removal of water by electro-osmosis was gradually increased with the duration of the process. In fig. 3 it can be seen that increase the voltage difference with respect to time, the rate of dewatering increases continuously. It can also be seen that at $60 \mathrm{~V}$, the volume of dewatering is increased sharply upto time $15 \mathrm{~min}$ and after that the dewatering rate is become sluggish as compared to applied $50 \mathrm{~V}$. This can be attributed to the rate of dewatering is gradually become slower due to the saturation of the moisture content of the coal sludge. Whereas, in case of $50 \mathrm{~V}$, the rate of dewatering is increased continuously upto 30 min without any change of rate of dewatering.

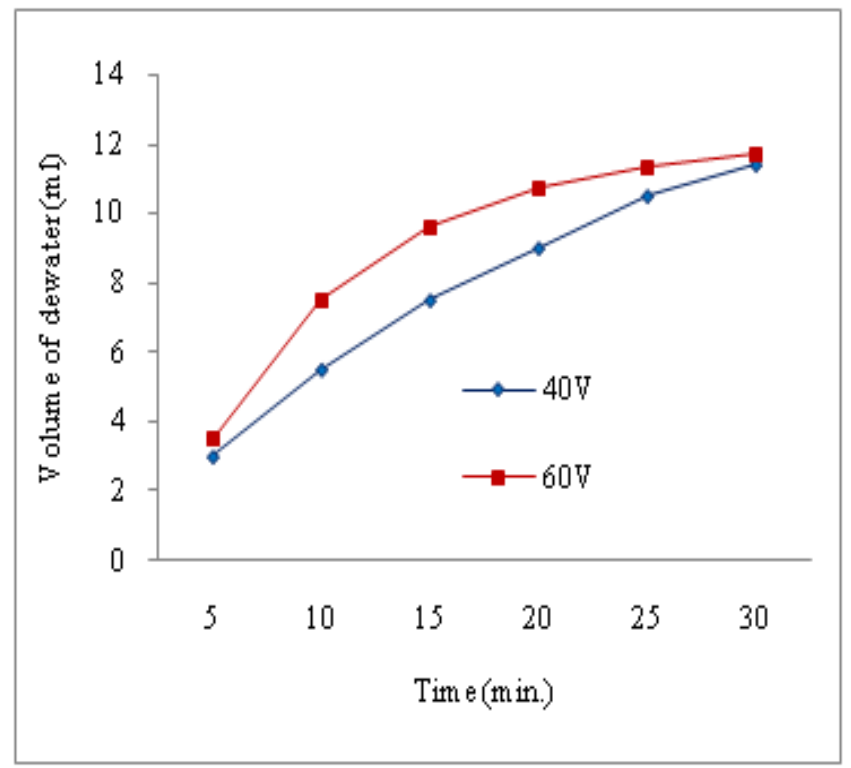

Fig-3: Relation between the volume of water removed and the duration of the process

\subsection{Effect of Electric Field on Electro-Osmotic Dewatering}

Fig. 4 shows that due to the increase of potential difference between two electrodes the volume of water removed by electro-osmosis is gradually decrease whereas the rate of volume of water evaporation from the hot anode surface is gradually increases. Consequently, it was observed that the heat generation in the electrodes surface was increased and the conduction effect evaporate the water from the hot surface rapidly increases with the increasing of voltage difference. 


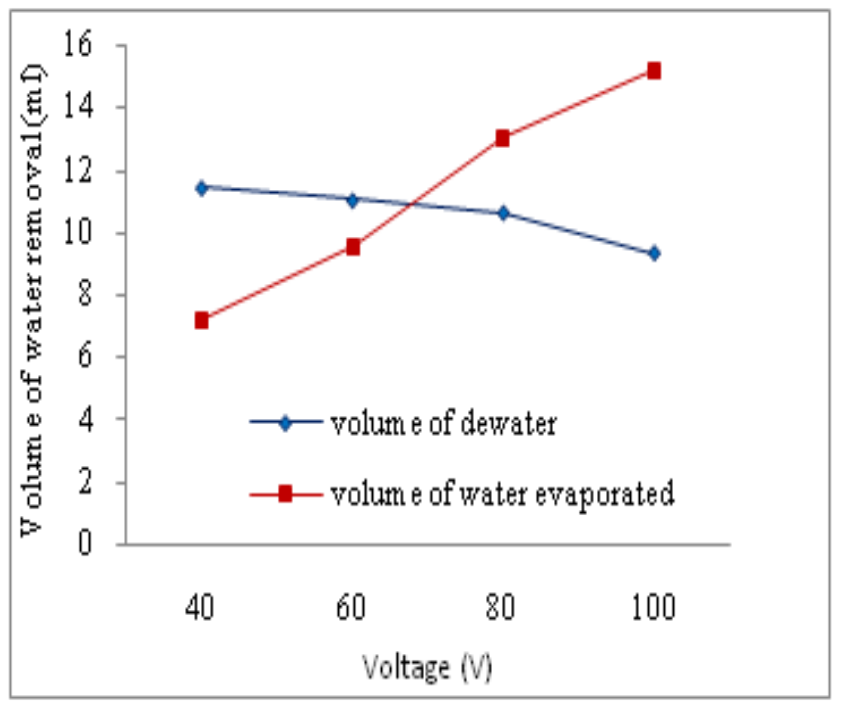

\subsection{Effect of Electrodes Potential Difference On}

\section{Moisture Content And Energy Consumptions Of}

\section{Coal Sludge}

In fig. 5 , it is shown that with the increase of voltage the $\%$ moisture content of coal sludge after process is gradually reduced. This result flow the Helmholtz-Smoluchouski theory [7], which states that with increase of electric field the moisture content of the sludge decrease. Schmid theory states that the rate of dewatering is affected by the zeta potential of the sludge particle [7]. The pattern of the curves in fig. 5 follows this theory. The increasing concentration of $\mathrm{NaOH}$ solution ensure the increasing zeta potential of the sludge, hence increase the rate of dewatering and reduced the moisture content of the sludge. In fig. 6, the comparison study of energy consumption with respect to voltage as well as concentration of $\mathrm{NaOH}$ solution is shown. It is found that there is a proportional relation between energy consumption and potential difference. But with the increase of concentration of $\mathrm{NaOH}$, for each voltage the energy consumption get reduced.

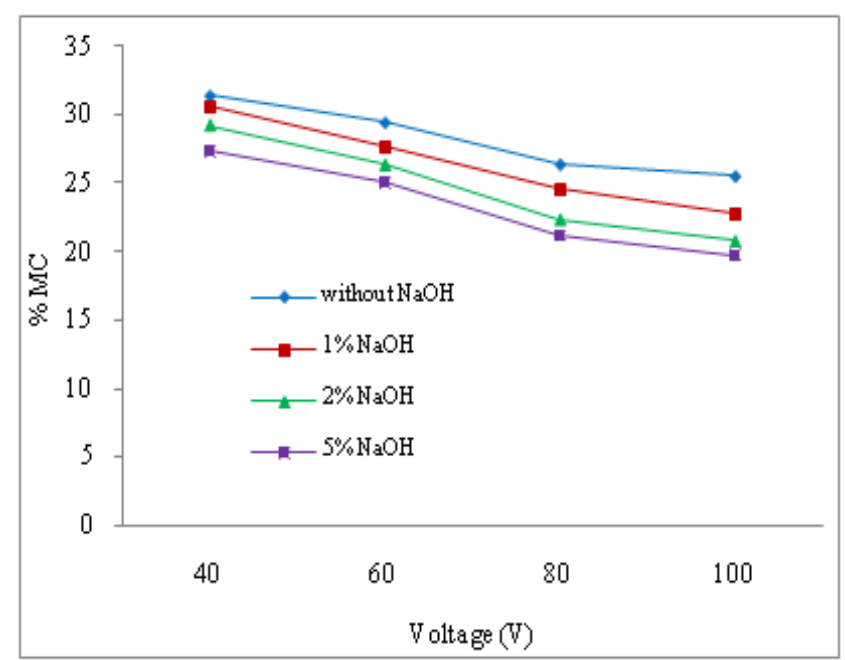

Fig-5: Variation of \% moisture content of coal sludge after EOD with the concentration of $\mathrm{NaOH}$ solution and voltage

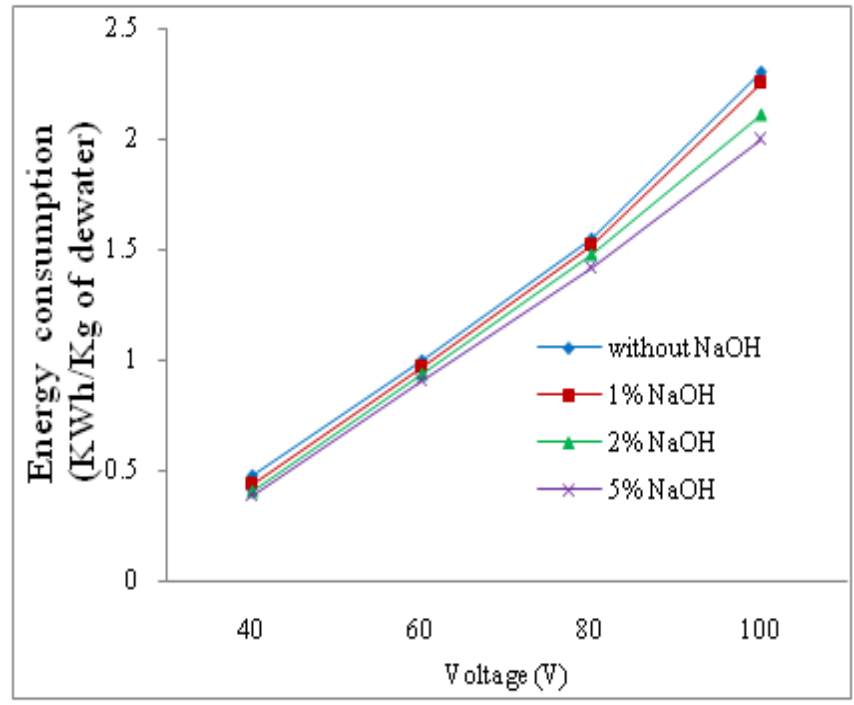

Fig-6: Variation of energy consumption of dewatering process with concentration of $\mathrm{NaOH}$ solution and voltage.

For example, at $100 \mathrm{~V}$ to remove the same amount of water energy required without adding $\mathrm{NaOH}$ solution to sludge is $5.9 \mathrm{KWh} / \mathrm{Kg}$ of dewater and that of with $5 \%(\mathrm{w} / \mathrm{v}) \mathrm{NaOH}$ solution is $5.0 \mathrm{KWh} / \mathrm{Kg}$ of dewater. Approximately, $15 \%$ energy consumption can be reduced only by adding $5 \%$ $\mathrm{NaOH}$ solution.

\section{CONCLUSSIONS}

It is observed that the increase of time and applied potential difference the rate of water remove and energy consumption increase. However, in addition of $\mathrm{NaOH}$ solution with the sludge can reduce the energy consumtion and enhance the dewatering rate. As the voltage is increased the heat generation at the electrodes is enhance, thus the amount of water evaporated is more than the water removed by electroosmosis. That ensure some amount of heat loss. Further modification of this process is needed to prevent that heat loss. Compare to the thermal processing of a sludge, the energy required approximately 54\% less to get same amout of moisture content of the sludge. Further research and details analysis is needed to optimize the effecting factors of the process

\section{REFERENCES}

[1]. Chi Kit, MOK, Design and modelling of electroosmotic dewatering, University of Newcastle upon Tyne School of Civil Engineering and Geosciences, August 2006, Thesis L8276.

[2]. Pavel Stasta, Jaroslav Boran, Ladislav Bebar, Petr Stehlik, Jaroslav Oral, Thermal processing of sewage sludge, Applied Thermal Engineering 26 (2006) 14201426.

[3]. Chia-Hung Hou, Electrical double layer formation in nanoporous carbon materials, Georgia Institute of Technology, April 2008.

[4]. Phạm Anh Tuấn, Sewage sludge electro-dewatering, Lappeenranta University of Technology, December 2011. 
[5]. Sridhar Ggopalakrishnan, Electroosmotic and combined fielddewatering of sludges, McGill University, Montreal, Quebec,Canada,August 1995.

[6]. Heath, L . W. and Demirel, T., Pressurizede lectroosnzoticd ewatering. Engineering foundation conference on flocculation sedimentation and consolidation.Sea Island, Georgia, 1984.

[7]. Afshin Asadi, Bujang B. K. Huat, Haslinda Nahazanan, Hamed A. Keykhah, Theory of Electroosmosis in Soil, Int. J. Electrochem. Sci., 8 (2013) 1016 - 1025 .

\section{BIOGRAPHIES}

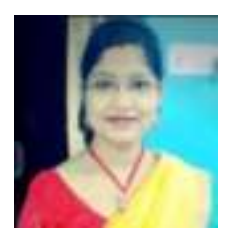

Ms. Sonali Samanta, is an Assistant Professor in Dept. of Chemical Engg., Haldia Institute of Technology. She received her $M$. Tech Degree from Jadavpur University, Kolkata. Her Research interest includes conventional and non-conventional energy technology.

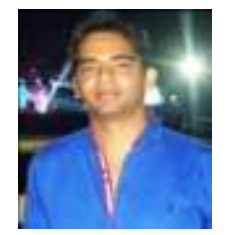

Mr. Piyush Kr. Gupta, 4th Year B. Tech Students in Chemical Engg. Dept., Haldia Institute of Technology.

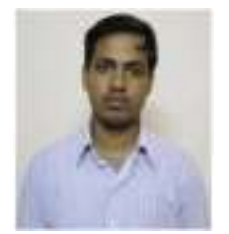

Dr. Avijit Ghosh, received his $\mathrm{PhD}$ degree from IIT Guwahati and M.Tech from Calcutta University. His research interest in the energy conversion device, graphene synthesis and its application, fuel cell. He has published 6 international peer review high impact factor journals and more than 16 national and international conferences proceedings. 